\title{
A regenerative high-rise tower in Shreveport, Louisiana for community renewal international
}

\author{
M. Garrison \\ School of Architecture, The University of Texas at Austin, USA
}

\begin{abstract}
Zero Net Energy Buildings are increasingly being designed and constructed in response to the demand for sustainable buildings. But, we must now go beyond merely sustaining our environment for future generations we must provide regenerative designs that restore our natural environment. This paper will document the design of a regenerative high-rise tower in Shreveport, Louisiana, which will serve as a facility to train individuals in a non-profit organization's renewal strategies and demonstrate by example the pedagogy of regenerative design.

The 16-story structure - built in the 1950s and named the Petroleum Tower, reflecting the commodity that then ruled the local economy - was vacant and asbestos-laden when given to the non-profit Community Renewal International (CRI) in 2001. In 2006, funded by a grant from the U.S. Environmental Protection Agency, workers removed the asbestos. Through a follow up grant from the U.S. Department of Energy to support the design process of a new CRI headquarters building, the University of Texas at Austin School of Architecture completed architectural design studies for the building renewal. The principles of this new design include: day lighting, envelope configuration, building integrated photovoltaic systems, green surfaces, ventilation strategies, advanced mechanical cooling systems, regenerative elevator systems, energy management systems, water harvesting, grey water systems, trigeneration systems and a combined heating, hot water and power biodiesel plant.
\end{abstract}

Keywords: high-rise tower, regenerative design, renewal. 


\section{Introduction}

Shreveport, Louisiana was one of the original U.S. oil-boom cities, with oil discoveries dating back to the 1870 s. The oil industry brought great wealth to Shreveport but in the 1980s, the oil and gas industry in northwest Louisiana suffered a large economic downturn, and many companies cut back jobs or went out of business. Shreveport suffered severely from this recession, and many residents left the area. In the 1980s and 1990s Shreveport experienced both a mass exodus of businesses from the downtown area and a lot of decay, crime, unemployment and other problems in low-income, inner-city neighbourhoods. The substantial population decline of the 1980s and early 1990s contributed to a realization that city leaders needed to establish programs of community renewal.

In 1994 Shreveport Community Renewal, a faith-based nondenominational and non-profit organization was established under the direction of Rev. Grady S. "Mack" McCarter, with the goal to reduce social isolation in distressed areas of Shreveport, and adjacent Bossier City and to disseminate its model of renewal to other cities. In January 2008, Shreveport-Bossier Community Renewal changed its name to Community Renewal International (CRI) to reflect the organization's growing local, national and international focus.

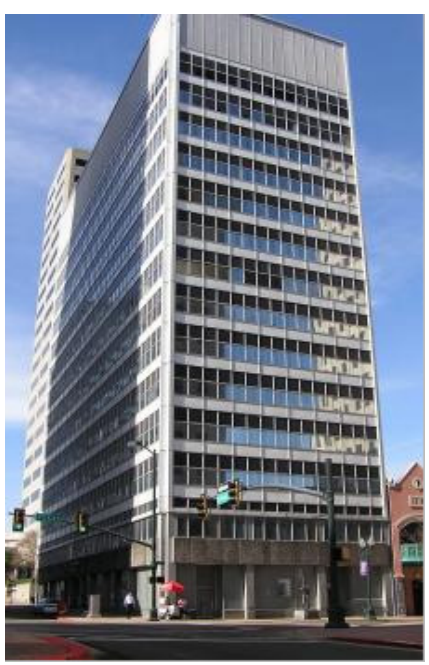

Figure 1: $\quad$ Petroleum tower.

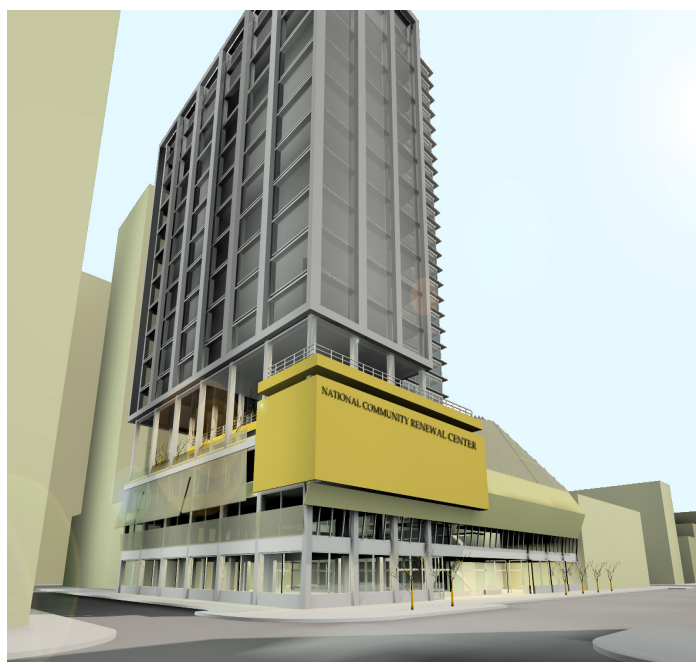

Figure 2: CRI tower renewal design (Namit).

\section{Community renewal international tower}

In response to the success of CRI programs, McCarter and his staff have initiated plans to convert a donated, vacant downtown Shreveport office building into a 
facility to train individuals in the organization's renewal philosophy and strategies. The CRI program calls for a headquarters building to be a demonstration of renewal, a symbol that reflects the purpose and spirit lifting qualities that inspire rebuilding quality communities. Community Renewal International will bring civic leaders from across the nation and the world to Shreveport to learn more about building and restoring safe and caring communities. The Centre will serve as a comprehensive facility providing training and technical support for community leaders who want to apply the model established by Community Renewal International in their own city. The building will house offices, conference centres, classrooms, a library, museum, gift shop, guest rooms for overnight accommodations and support facilities. The building itself, the historic Petroleum Tower, is also a symbol of renewal by using solar panels, taking advantage of day lighting, recycling its wastewater and incorporating other energy-efficient measures the building is designed to connect green building and community renewal. The self-sustaining building is expected to be the first in Louisiana to earn a platinum-certified rating, which is the highest Leadership in Energy and Environmental Design (LEED) standard.

The CRI regenerative design process began with a decision to forego construction of a new facility in favour of renovating an existing structure. The existing Petroleum Tower was gutted down to its concrete frame, preserving the embodied energy in the existing concrete structure. Starting from a standard energy code based design strategy for the 16-story, 140,000 square foot tower and 140,000 square foot addition; a baseline building energy performance standard load was calculated at 500 tons $(12,000 \mathrm{BTUH} /$ ton) of HVAC load and $500 \mathrm{~kW}$ of power load. This baseline is the energy load that would normally be required to support the environmental technologies needed to keep the building occupants comfortable and productive in the hot and humid northwest Louisiana climate. It is the primary goal of the design team to greatly reduce this load through energy conservation and green building design in order to achieve both power and conditioning through on-site sources so that the building could go beyond being a Zero Net Energy design and could generate excess power and water to feed back into the city grid.

With "energy conservation first" as a major green building goal for the CRI tower, the design team employed six major strategies to achieve a regenerative building design. The first strategy was to reduce the lighting load of the building by $50 \%$ through a combination of more energy efficient lighting systems, direct/indirect lighting design strategies and the extensive control of day lighting. In combination these technologies reduced the power load of the building to 429 tons of HVAC and $250 \mathrm{KW}$ of power

The second strategy of energy reduction was to reduce the HVAC load by an additional $20 \%$ through enhanced building orientation and building envelope configuration. A second 140,000 square foot tower and service core are to be added adjacent to the existing 140,000 square foot Petroleum Tower. Carefully proportioned and massed the new CRI tower design aesthetic breaks the building's mass into smaller components to be respectful of the building's historic downtown context. The composite tower's new iconic form will then be 


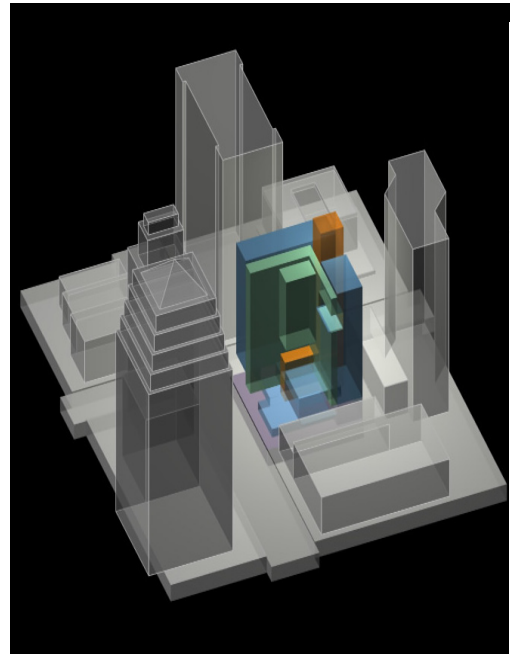

Figure 3: Building orientation (Pearson \& Lee).

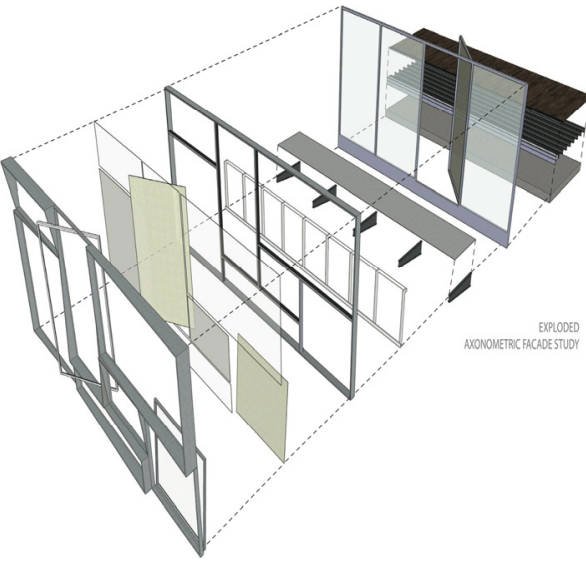

Figure 4: Envelope configuration (Crum, Buono \& Cheng).

achieved by replacing the existing steel and glass curtain wall with a combination of well oriented Building Integrated Photovoltaic (BIPV) panels and high-performance smart double-glazing curtain wall technologies that are self-shading and permit enhanced day lighting while preventing unwanted heat and glare through a process of refracting the changing angles of sunlight. The new interiors will have a reduced glass-to-core depth to enhance delighting. In combination these technologies will reduce the HVAC load of the building to 343 tons and lower the power load to $305 \mathrm{~kW}$.

The third process of energy reduction includes a combination of more enhanced building envelope designs including an additional $11 \%$ reduction in the building HVAC load through the use of ventilated double-envelope facades, and an additional $10 \%$ reduction in HVAC through the use of natural ventilation when the exterior climate is within the bioclimatic comfort zone. When the prevailing breeze is inadequate for ventilation, solar-induced stack ventilation coupled with a groundwater source heat exchanger will be facilitated through a solar chimney chase adjacent to the building core. In addition there is another $8 \%$ HVAC reduction through the use of extensive green roofing and green vertical surfaces that also reduce the urban heat island effect. In combination these technologies reduce the HVAC load of the building to 190 tons and the reduction in HVAC load will correspond to a reduced power load down to 200 $\mathrm{kW}$.

The fourth process of energy reduction features state-of-the-art, mechanical systems including, a 30\% HVAC reduction through the use of heat pump technology in combination with a district hot water loop and a four-pipe fan coil 


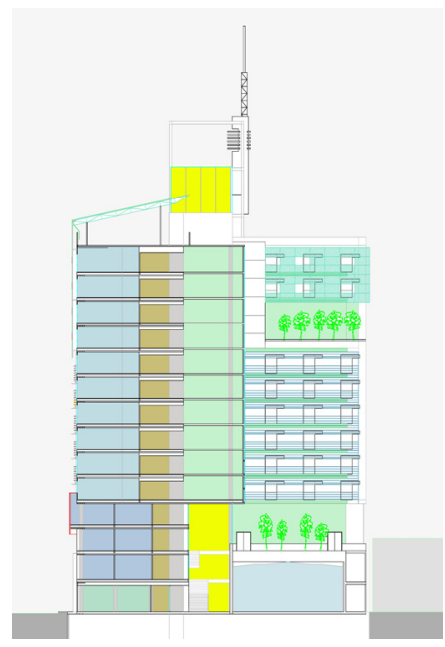

Figure 5: Building section Figure 6: (Pearson \& Lee).

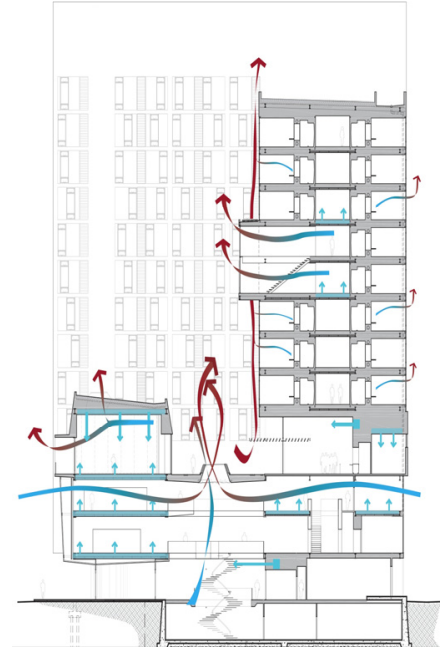

Stack ventilation (Nolan \& McDaris).

unit located in each hotel room to provide individual comfort control. In addition another 20\% HVAC reduction can be achieved through the use of filtered under floor displacement air conditioning with personal environmental control at each workstation in the office floors. These systems are combined with energy recovery ventilation systems to assure adequate levels of fresh air. Acting together these energy-efficient mechanical systems will reduce the HVAC load to 100 tons and lower the power load to $130 \mathrm{~kW}$.

The fifth strategy achieves an additional $20 \%$ in energy savings through a computer-controlled Energy Management System (EMS). This system combines computer control with network lighting control, chillers, fans, vents, alarms, hotel key control and other information and environmental control systems to improve efficiency. Utilizing a basement data centre the building tenants will have more bandwidth capacity to accommodate smarter information systems and network growth. In combination this smart technology will reduce the HVAC load to 80 tons and reduce the power load to $120 \mathrm{~kW}$.

The sixth strategy for saving energy employs the use of energy-efficient equipment including efficient hotel room appliances, energy star kitchen equipment, efficient office equipment and regenerative elevator equipment systems. These systems can reduce the building power load down to only 100 $\mathrm{kW}$.

To meet the remaining required on site energy demands of the CRI tower, a 2-megawat low-emission trigeneration (combined heating, power and hot water) biodiesel plant that provides a clean, efficient power will be located on the rooftop of the CRI tower. The trigeneration plant will provide all the hot water needs and excess electrical power will be feed into to the municipal electrical 


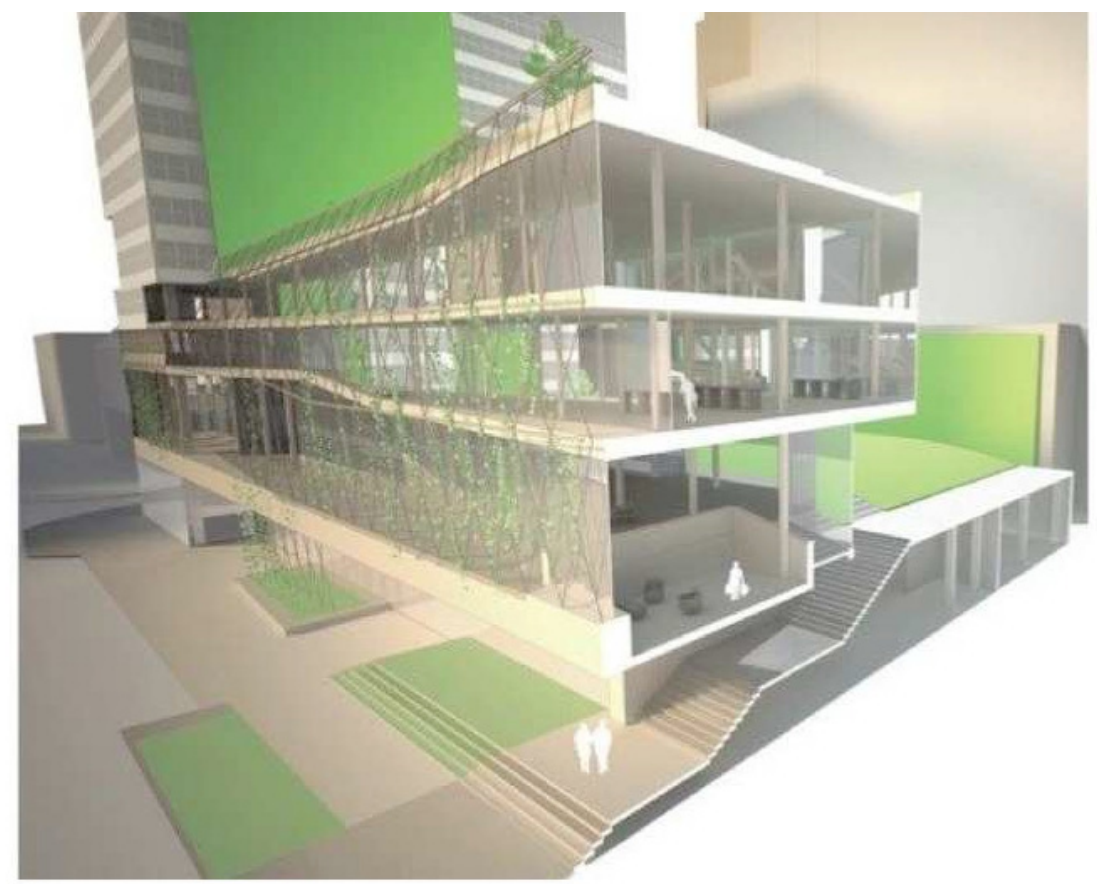

Figure 7: $\quad$ Green roof and vertical green walls (Gilliam, Foursquare).

grid. The CRI tower is also designed to save millions of gallons of water annually due to the installation of a gray water recycling system that collects and stores rainwater, bathroom grey water, recycles wastewater, collects cooling coil and district steam condensate, and recycles this water for use by the cooling tower and for flushing toilets. An under-slab drainage system captures water that infiltrates under the slab on grade, and that water is recycled into the gray water system.

\section{Conclusions}

With the addition of on site combined heating and power plants Zero Net Energy buildings will become more ubiquitous in large buildings. The CRI tower design will go beyond ZNE, moving toward regenerative design, because it will feed power back into the utility grid and will serve as a model to regenerate downtown Shreveport, Louisiana. Intelligent application of advanced regenerative technologies for the CRI tower in conjunction with innovative environmental systems results in significant energy savings as well as an improvement in renewing communities. The design of the CRI tower is poised at a time of transformation in energy policy and architectural design in which integrated approaches to regenerative technologies enable new degrees of environmental response and ecological effectiveness. When designed carefully, 
regenerative designs will not represent additional life cycle costs, because operational costs will be lower, and utility energy costs can be reduced compared with conventional solutions. Given the current urgency on land use impact, pollution concerning material and energy resources, life cycle costs, and renewability, it is time to initiate comprehensive and wide reaching initiatives for conservation, renewable design innovations and regenerative technologies in the built environment.

Cities across the world are already building their own programs based on the Shreveport model. Community Renewal initiatives are now underway in Austin and Abilene Texas; Baton Rouge, La.; Knoxville, Tenn., and other cities. And in Cameroon, Africa, the chiefs of five remote villages have united to bring Community Renewal to their corner of the world. Community Renewal has signed a cooperative agreement with OCCAM, the Observatory for Cultural and Audiovisual Communication, making CRI the community-building model for the Info poverty Programme worldwide. OCCAM, is a charter office within the United Nations, and coordinates information on alternatives to poverty.

\section{References}

[1] Chen, Allan, The New York Times Building: Designing for Energy Efficiency Through Daylighting Research, Science Beat, Berkeley Lab, February 17, 2004.

[2] Garrison, M., Regenerative High-Rise Designs for the CRI Tower, School of Architecture, The University of Texas at Austin, 2010.

[3] GBD Architects, Oregon Sustainability Center: The World's First Urban High-Rise Net Zero Living Building, The Oregon Way, Portland Ore. 2009.

[4] Kwok, A., Zero Net Energy Workshop and Design Charrette, The University of Oregon Department of Architecture and the Center for Housing Innovation, Portland, Oregon. 2009.

[5] Laing, A. and Duffy, F., New Environments for Working: The Redesign Of Offices And Environmental Systems for New Ways of Working, Taylor \& Francis Group, 1998.

[6] Lyle, J. T., Regenerative Design for Sustainable Development, Wiley \& Sons, 1993.

[7] Sinclair, R., Phillips D. and Mezhibovski V., Ventilating Facades: Pearl River Tower, ASHRAE Journal, April 2009.

[8] Smith, A., The Architecture of Adrian Smith, SOM: Toward a Sustainable Future, Images Publishing Group Pty Ltd. 2007.

[9] Transsolar Climate Engineering, High Comfort Low Impact, FMO Publishers, 2009.

[10] Wood, A., ed. Best Tall Buildings 2008: Ctbuh International Award Projects, Butterworth-heinemann, 2008. 